\title{
Supporting Recruitment and Retention of Young African-American and Hispanic Fathers in Community-Based Parenting Interventions Research
}

\author{
Cristina Mogro-Wilson \\ Alysse M. Loomis \\ Crystal Hayes \\ Aubri Drake \\ Melanie Martin-Peele \\ Judith Fifield
}

\begin{abstract}
Few studies to date have provided strategies for maintaining low rates of attrition when conducting longitudinal, epidemiological, or community-based research with young, minority, urban fathers. This paper highlights lessons learned from a 5-year randomized controlled trial of a fatherhood intervention that designed and implemented state-of-the-art and culturally relevant recruitment and retention methods with 348 young fathers ages 15 to 25. Qualitative findings are drawn from interviews with fathers who had been enrolled in the fatherhood intervention $(n=10)$. While traditional recruitment and retention methods, such as incentives, were employed in this study, non-traditional methods were used as well, such as intensive community outreach, staff relationship development, recruiting specialists, and flexible contact methods. These methods were found to be helpful to young fathers in the study. Future research should incorporate, and further study, such non-traditional methods for recruiting young, minority, urban fathers into studies of parenting programs, including randomized control trials, to improve services for this underserved population.
\end{abstract}

Keywords: Fathers; community-based research; recruitment; parenting

Including fathers in parenting interventions is important to children's well-being. Fathers play an important role in children's development and competence (Dubowitz et al., 2001), and interventions that include both parents have more positive impacts on parenting practices and children's outcomes (Lundahl, Tollefson, Risser, \& Lovejoy, 2004). Twentyfive percent of African American males, and 19\% of Hispanic males father children before the age of 20 (Martinez, Chandra, Abma, Jones, \& Mosher, 2006). Young fathers, who have children as adolescents or young adults, are particularly important to engage in parenting programs, as they are at higher risk for future unintended pregnancy and other health risk behaviors compared to older fathers (Khurana \& Gavazzi, 2011). Despite the risks associated with early fatherhood, there are limited pregnancy prevention and parenting programs targeted at young fathers (Aggleton \& Campbell, 2000; Lewin, Mitchell, Burrell, Beers, \& Duggan, 2011). For those programs that do exist, there is a need for research examining recruitment and retention, particularly for minority young fathers (Trivedi, Brooks, Bunn, \& Graham, 2009) who have consistently higher birth rates compared to white fathers ages 15-25 years of age (Hamilton, Martin, \& Osterman, 2016).

Cristina Mogro-Wilson, PhD, MSW is an Associate Professor, Alysse M. Loomis, LCSW and Crystal Hayes, MSW, are Doctoral Candidates, School of Social Work, University of Connecticut, Hartford, CT. Aubri Drake is Clinical Research Administrative Coordinator, Baystate State Health System, Springfield, MA. Melanie Martin-Peele is at the Health Disparities Institute, St. Francis Health Care, Hartford, CT. Judith Fifield is at the Health Disparities Institute, University of Connecticut Health Center, Farmington, CT. 
The parenting challenges that young minority fathers face highlight the need to focus on ways to improve recruitment and retention of these fathers into pregnancy prevention and other parenting programs.

\section{Young, Low-Income, Minority Fathers}

Young fathers are at increased risk for additional unintended pregnancy compared to young men the same age who are not fathers (Burrus, 2018; Centers for Disease Control, 2013). Young fathers are also at higher risk for participating in sexually risky behaviors, such as not using condoms that could lead to subsequent pregnancies and HIV/AIDS or other sexually transmitted diseases (Bronte-Tinkew, Burkhauser, \& Metz, 2007; MogroWilson et al., 2018). Young men who become fathers in their teens are more likely to live in poverty, encounter school hardships, leave school prior to graduation, and other negative consequences compared to their peers who are not fathers (Xie, Cairns, \& Cairns, 2001). However, research shows that some of the negative consequences for young fathers can be tempered by parenting programs that help fathers become positively involved in their children's lives and well-being (Buston, Parkes, Thomson, Wight, \& Fenton, 2012; Carlson \& Magnuson, 2011; Jeynes, 2015; Milkie \& Denny, 2014; Palm \& Fagan, 2008).

\section{Parenting Programs with Fathers}

Although parenting programs benefit fathers and their children, recruitment of fathers into such programs remains a challenge for fatherhood program providers. Studies on rates of father participation reflect this difficulty. A meta-analysis of the parenting program Triple $\mathrm{P}$, which targets both fathers and mothers, analyzed randomized controlled trials of Triple P that either specifically targeted fathers or included fathers (Fletcher, Freeman, \& Matthey, 2011). This analysis found that out of 4,959 participants in 21 studies across several countries, only $20 \%$ of the participants were fathers. Furthermore, a systematic review of father participation in child maltreatment prevention programs, all of which involved a parenting education component, found father participation rates to be less than 30\% (Smith, Duggan, Bair-Merritt, \& Cox, 2012). In a study of providers of parenting programs, one-third of providers reported that fathers rarely attended programs (Tully et al., 2018). These studies reviewed father participation without differentiating between races and ethnic groups. While data on rates of African American and Latinx father participation in parenting programs are scant, there is sufficient evidence that participation rates among minority parents may be lower than among other groups (Caldwell, Bell, Brooks, Ward, \& Jennings, 2011).

A few studies have suggested strategies for maintaining low rates of attrition when conducting longitudinal, epidemiological, or community-based research among fathers (Anderson, Kohler, \& Letiecq, 2002; Caldwell et al., 2011; Gordon et al., 2012; MogroWilson \& Fifield, 2018). Barriers to engaging in parenting interventions identified by fathers include fear of opening up to other men in groups, difficulty balancing employment and parenting programs, and a lack of tangible social supports within parenting programs that can alleviate financial stressors (Anderson et al., 2002). Provider experience and organizational support, such as emphasizing the inclusion of fathers in program materials, are predictive of increased father engagement in parenting interventions (Tully et al., 
2018). In focus groups of providers and African-American fathers not currently participating in parenting programs, providers identified that word-of-mouth, where participants tell other potential participants about the parenting programs, and targeted recruitment, where individuals are sought out for participation based on key characteristics or relationships with agencies, are effective recruitment strategies for fathers (Stahlschmidt, Threlfall, Seay, Lewis, \& Kohl, 2013). In these focus groups, fathers identified increased advertising (not only targeted) and tangible incentives, such as transportation were also key to overcoming barriers to engaging fathers in parenting programs.

Recruitment strategies have been sought out from urban African-American fathers not currently engaged in a parenting program (Stahlschmidt et al., 2013) and fathers involved in parenting programs (rather than fatherhood programs specifically; Anderson et al., 2002; Fletcher et al., 2011). However, no information is currently available specific to the recruitment and retention of young urban minority fathers in pregnancy prevention and parenting programs. Therefore, there is little systematic discussion on how to successfully implement parenting and prevention strategies among young urban fathers. An assessment of methodological strategies for conducting longitudinal prevention research with young fathers is necessary to advance the science of pregnancy prevention and fatherhood and address the risks uniquely associated with early parenting.

\section{Importance of Retention in Parenting Programs}

Agencies offering parenting programs to young parents have increasingly been challenged to create evidence-based practices in their settings. In order to establish evidence for an intervention, agencies are often expected to use randomized controlled designs that collect longitudinal data with a focus on retention into such trials. Much of the research on participant retention has focused on randomized controlled trials of diseases such as diabetes, heart disease, and cancer (Bailey, Bieniasz, Kmak, Brenner, \& Ruffin, 2004; Froelicher et al., 2003; Katz et al., 2001; Parra-Medina et al., 2004) with less of an emphasis on exploring participant enrollment and retention in prevention studies. However, retention rates in pregnancy prevention studies range from $24-76 \%$ (Corcoran \& Pillai, 2007), a stark difference from retention rates of 59-99\% common in clinical studies (Robinson, Dennison, Wayman, Pronovost, \& Needham, 2007). The difference in retention rates may reflect a difference in motivation for study participation. For example, study participants in health care research are often recruited from clinical settings in institutions where they are patients and thus highly accessible. In conventional clinical studies, a patient may continue their participation on the basis of anticipated health benefits. In contrast, in prevention intervention studies, participants may be less likely to see an immediate need for the program, and program benefits may be less clear or take longer to emerge (Becker, Hogue, \& Liddle, 2002; Spoth \& Redmond, 2000).

Motivations and benefits for young urban fathers in longitudinal prevention intervention studies are unclear and often confounded by issues of income, education, race, and social capital. There is a legacy of distrust, bias, negative perceptions, and poor communication for African American and Latinx communities when it comes to interacting with health care service providers (Corbie-Smith, Thomas, \& St. George, 2002). Some 
African Americans have reported they do not feel respected by providers, often leading to mistrust of anyone related to health care services or research (Gordon et al., 2006). There is also a documented lack of communication between minority communities and their providers, which further contributes to mistrust of services being offered, ultimately leading to underutilization of those services (Travaline, Ruchinskas, \& D'Alonzo, 2005). For community-based programs, challenges around mistrust must be overcome in order to build public health studies that will lead to better services and improved outcomes within low-income minority communities. This is particularly important given that government funding agencies are requiring treatment and prevention grantees to have retention rates of at least $80 \%$ for their projects to be considered "successful." Research on recruitment and enrollment must address the value of multicultural community organizing and engagement. For example, events should involve opportunities for community celebration with families as a medium for community collaboration and outreach.. These strategies may result in higher retention rates, and thus more valid research and better opportunities for care within marginalized communities.

\section{Current Study}

Longitudinal studies of young adult pregnancy prevention programs generally have been associated with prevention in school-based settings, where the targeted youth are a captured population, enrolled and attending school. Additionally, such studies have typically primarily focused on females (Aggleton \& Campbell, 2000; Trivedi, Bunn, Graham, \& Wentz, 2007). Longitudinal studies of hidden and hard-to-reach populations, such as young fathers, are less common. Longitudinal studies among these subpopulations require the use of multiple innovative retention techniques. These techniques are specific to each subgroup and their respective contexts. This paper seeks to add to the scant literature base regarding recruitment, enrollment, and retention in studies with young, minority fathers using the experience and lessons learned in a five-year RCT of a parenting intervention implemented with low-income minority fathers that designed and implemented novel recruitment methods.

\section{Methods}

\section{Intervention Design}

The current study reports on experiences and findings from a larger collaborative study designed and undertaken by a university-agency partnership in Connecticut. Agency staff recruited and randomized participants, conducted the intervention, and collected data with training. The university partner provided scientific quality control monitoring, data management, and data analytics. Between 2011 and 2016, 348 fathers aged 15-25 were enrolled from a city in the northeastern United States, in a highly dense low-income area. Eligible participants were males ages 15-25 who had fathered one or more children with a female under the age of 21 at the time of enrollment. Approximately $62 \%(n=215)$ were Hispanic, 38\% ( $\mathrm{n}=132)$ were African-American or Black, $5 \%(\mathrm{n}=17)$ were white, $2 \%(\mathrm{n}=7)$ were American Indian or Alaska Native. At the start of the study, 35\% $(n=121)$ had a high school diploma, and 38\% $(\mathrm{n}=132)$ were still in school and all were unmarried. Fathers were 
randomized by enrollment wave into the intervention condition, FatherWorks, or to the control condition, the standard-of-care program 24/7 Dads. The intervention condition, FatherWorks, was comprised of five components: 1) a 15-session parenting intervention, Supporting Father Involvement (SFI) group (Cowan, Cowan, Pruett, Pruett, \& Wong, 2009); 2) a 13-session employment class, Supported Employment (SE; Farr \& Pavlicko, 2006); 3) access to a 120-hour paid internship; 4) biweekly case management; and 5) access to behavioral health services. The Supporting Father Involvement (SFI) parenting intervention met once a week with 120 minutes of group (Cowan et al., 2009). The Supportive Employment (SE) classes met once a week with 120 minutes of group (Farr \& Pavlicko, 2006). Individual case management occurred biweekly for 60 minutes. The control condition, 24/7 Dads, is comprised of three components: 1) a 15 session parenting education class (24/7 Dads) (Chacon, Patterson, Brown, \& Bavolek, 2003); 2) problemfocused case management; and 3) outside referrals to other services, including behavioral health, if desired. The 24/7 Dads parenting education classes are based on the 24/7 Dads AM curriculum (Chacon et al., 2003). The 24/7 Dads parenting education classes occurred once a week with 120 minutes of group. Problem-focused case management was available on an emergency basis. Survey data on demographics, safe sex practices, and parenting attitudes/behaviors was collected at pre-intervention, at post-intervention (14 weeks), and four, eight and 12 months after intervention. Participants were given gift cards of $\$ 10, \$ 15$, $\$ 20, \$ 30$, and $\$ 50$ for each completed data collection point.

Process Evaluation Data and Interview Groups. Information was gathered from study participants in the Fatherworks group regarding successful strategies, additional barriers, and future suggestions to increase recruitment, enrollment, and retention of young, urban, minority fathers into the identified prevention programs. Interviews of two fathers per group were conducted by the university partner to explore fathers' perceptions about the parenting programs and strategies to engage fathers in these programs. These interviews were conducted during the second through fourth year of the five-year implementation period and recruited fathers who were close to completion of the Fatherworks program. Prospective participants were recruited via flyers posted and distributed at the community agency's parenting programs. To make attendance easier, interviews were scheduled directly after the day's parenting group. A semi-structured guide was used to discuss the FatherWorks program. Questions covered topics ranging from issues related to parenting and co-parenting to services provided by FatherWorks, from what they believed went well to what they believe did not go well in the program (see Table 1 for the full list of questions). Specifically, the interview guide sought to elicit information about the father's access and barriers to services to determine: 1) how the participant became aware of the program (recruitment), 2) perception of preliminary contacts with program staff (enrollment), 3) overall experience with the program, 4) successful strategies and barriers to continued attendance (retention), and 5) suggestions for ways to engage fathers in the programs (suggestions for future recruitment, enrollment, and retention). 
Table 1. Group Interview Questions

1. How did you first learn about the FatherWorks Program?

2. What was it like for you the first time you talked with a FatherWorks staff person about the program?

3. What information did the staff person give you, like the reasons you might be eligible to be in the study, when the program would be starting, what you would get out of it, etc.?

4. What services have you used in the program?

5. What was your experience with the program staff, like case managers and group leaders?

6 . What do you think were the strengths of the services offered by the program?

7. What do you think were the weaknesses of the services offered by the program?

8. What were your experiences with feeling understood or accepted, or not, by the program staff?

9. What made coming to group easier for you?

10. What made coming to group difficult for you?

11. Would you recommend the program to someone who's a young dad? Why or why not?

12. Do you think your parenting has changed since you started the program? If so, in what ways?

13. In one of the survey questions, the respondent is asked the number of times they've had sex in the past 3 months (90 days). Quite a few people answered "a lot." What number seems like "a lot" to you? If you're willing to share that number with us, please write it down on the piece of paper. Don't write anything else on the paper; we want it to be anonymous.

14. Is there anything else you'd like to tell us about?

All interview group facilitators received comprehensive training in qualitative interview methodology. Training included strategies for reducing threats to the trustworthiness of qualitative data, including strategies for reducing research and respondent bias (Padgett, 2008). Five interview groups containing 2 participants each (small group size due to the volume of their answers and length of interviews) were held at varying times and days at the community-based agency providing the support services to fathers. Interviews were approximately 90-110 minutes in duration. The participants $(n=10)$ were each given a $\$ 15$ gift card from Walgreens or Walmart. The fathers were informed that there were no right or wrong answers and to feel free to speak as openly and honestly as possible. Fathers in need of transportation assistance were provided with transportation to and from the agency. Interviews were audio-recorded, transcribed, and coded using thematic analysis. This study was approved by the University of Connecticut's IRB (\#IE-12-018SO-2), and participants were consented using IRB-approved procedures.

Data Analysis. A database was developed consisting of the interview narratives. The process evaluation field notes were used to triangulate the analysis of the data to develop a comprehensive understanding of the context of fathers' experiences in the parenting program. Analysis was guided by Social Ecology theory (Bookchin, 2005) and used NVivo, a qualitative data analysis software. Data analysis was comprised of four inductive strategies (Miles, Huberman, \& Saldana, 2013). The first strategy, item level analysis, involved careful line-by-line reading of the narrative data (text files) and unrestricted initial coding. Items and categories were developed through the process of constant comparison (Miles et al., 2013). Specifically, the research team comprised of a faculty member, a doctoral student, and an MSW student, compared categories and classifications across the data. In this process, more general categories emerged. During this initial process, item codes were considered tentative and so were further explored in the next step. The second 
strategy, a pattern level of analysis, established linkages among the coded items, categories, and classifications in order to develop potential taxonomies or domains (Miles et al., 2013). Item codes that were not considered by the research team to have utility to the research aims were excluded. Based upon continuous dialogue with research members, selected codes were further collapsed or dropped from the analysis. The third strategy, the structural level of analysis, organized the relationships among the elucidated patterns of the data (taxonomies or domains) into structures. The fourth strategy, interpretation, allowed for wider theoretical meaning to structures within the theoretical framework of social ecology. All members of the research team were involved in data analysis by coding data first separately and then jointly. Emergent codes were based upon consensus and those that did not reach consensus were discussed at length. On a few occasions when consensus was not reached regarding specific codes, a fourth party was consulted. This process continued until the coders reached a consistent level of coding that was monitored by the faculty member.

\section{Results}

Community involvement, staff characteristics and relationships, frequent and flexible communication, and tangible program elements emerged as key themes related to supporting recruitment and retention with the fathers in this study. Key recruitment strategies included community outreach, social media campaigns, a designated recruitment specialist, and non-traditional recruitment strategies such as peer-to-peer recruiting. Successful retention strategies included helpful program elements, flexible methods of communication, and relationships with program staff. Suggestions were identified by fathers to address ongoing challenges to recruitment and retention in the study.

\section{Recruitment and Enrollment}

The recruitment-retention protocol developed for the study aimed to fuse evidencebased strategies with principles of social marketing. The study design called for stringent eligibility criteria due in part to funding requirements (e.g., money must be used to fund programs designed to reduce youth pregnancy). As restrictive eligibility criteria have been implicated as one of the main causes of nonparticipation in randomized controlled trials, an outreach plan was developed to recruit potential participants through three primary methods: (1) engagement of the community; (2) strategies to locate hard-to-reach populations; and (3) using culturally relevant materials. The strategies identified by program staff and participants that supported recruitment included intensive community outreach, identified staff roles for recruitment, and non-traditional recruitment methods, such as peer-to-peer recruiting.

Community outreach. The community-based agency conducted extensive community outreach, through support of a variety of events in the community, including a BBQ and a picnic, in attempts to be more involved within the community. These events provided the community with food, music, and entertainment as well as a platform to dispense recruitment materials for the study. Clinical staff were present to describe different services the agency provided. In addition, community collaborations with agencies allowed for informative presentations and referral information to be given to various organizations that provide services to youth and young adults (such as the State of 
Connecticut Department of Children and Families, Family Court, and other social service agencies). As part of a wider media and marketing campaign advertising its fatherhood services in general, the study site also conducted outreach about the FatherWorks program through a variety of media activities including: appearances on radio and television shows; online radio/TV shows; podcasts; in-person interviews; live streaming interviews; inperson gatherings of young fathers, their family members and friends, and those who provide services to and/or educate them; and social media such as Facebook, Twitter, Instagram, the agency's website, and other applicable websites. These recruitment strategies reflected a culturally relevant method of engaging young fathers.

Identified staff roles for recruitment and enrollment. The presence of a recruitment specialist, typically a graduate from the program, and the use of street teams, which included peer-to-peer referrals, assisted with community-level recruitment. The recruitment specialist was able to dedicate the majority of their time to locating potential participants. Recruitment staff spent hours getting names and contact information, following leads, calling and recalling numbers for months, going to locations where participants may frequent such as basketball courts, schools, hospitals, eateries, and so on. Graduate interns and street teams engaged in the community were able to provide referrals to the recruitment specialist. Recruitment messages in the study often emphasized four themes: 1) the value of the participant's own story; 2) confidentiality of collected information; 3) the potential positive impact of the program on their lives, and 4) the importance of the study data in evaluating how fathers matter in their children's lives. Staff worked hard to meet with fathers on their own terms, taking the time necessary to build relationships with them. One participant noted the benefits of a dedicated recruitment specialist who was able to connect personally with the individual, noting:

You know, it wasn't really like he was telling me about the program. He was, but at the same time, he was trying to like kinda get to know me too, and not make it so professional. You know what I mean? Like he's tryna sell me a program. You know what I'm saying? Like he's tryna, how you doing man you know, I hear you got a kid coming and stuff like that, you know what I mean? Like tryna get to know me, and I respected that. You know, 'cause not a lot of people have the ability to do that, you know. Make a job more than a job, so. And I respected that.

Building relationships with potential study participants both assisted in increasing buy-in for the community program and providing fathers with an outlet to voice their own goals and needs for the program. Enlisting staff with similar characteristics as the fathers in the study were identified as a strength in building relationships and supporting study recruitment and enrollment. As one young father shared, being able to identify with staff helped him connect with the program and also helped him succeed as a dad:

It's been pretty good, cause well, like, they're here to show us things, but like one of the staffs, he's 20 something. He's like almost our age, I think. So he talks about his experience too. The other two staffs, they're like in their 40's, so they also talk about they... when they was young, they like, how they was like, how we think we're crazy, when they was young they did crazier things as us too. They was like, everybody grows up almost the same. So then they start[ed] talking about they 
feelings. They start talking 'bout how they raised their kids, so, like, we all bond together.

While recruitment specialists, street-level recruitment, and taking time to build relationships may be time-consuming, these strategies were identified as positive and effective by fathers in this study. Another successful recruitment strategy was the support of peer-to-peer referrals. The use of peers and street teams helped to ease fears about participating in a research study.

\section{Retention}

Successful retention strategies included program elements, relationships with program staff, and flexible methods of communication.

Program elements. Several fathers expressed their appreciation for program elements in helping them set goals and meet their responsibilities as parents as a huge motivation for maintaining their enrollment with the program. One father said, "I kinda liked it. I came in... and me and him had a connection, 'cause, um, we was talking 'bout goals I should have, plans for the baby, and I told him all these plans I have." In addition to supporting fathers to meet their own identified goals, fathers discussed that the tangible benefits and incentives of the program, namely the participant incentives, employment training, and supportive case management referral services, allowed them to tangibly meet goals during the course of the program. One participant noted the way to recruit other fathers into the program was to highlight the tangible study elements:

Um, just letting them know, just flat out, like, listen, if you do this program, you can get some money in your pocket. It could give you a decent job to put some money in your pocket so you can support yourself and your family. If you need help dealing with school, we got you. If you need, what's the word I'm looking for, I don't know, but if you need help in school, we got you. If you need someone to talk to, we got you. If you hungry, we got you, you know what I mean? So, that's all of it right there. Like you get fed, you get paid, you get a higher sense of being, and that's basically it. Like what else can you really ask for? What else can you really ask for?

Program characteristics that allowed participants to meet personal, tangible goals were identified as helpful in supporting fathers to continue in the program, even after the program had concluded. Incentives for participations were also identified as positive strategies to support retention.

Staff relationships. Just as staff trust and relationships were identified by participants as a positive strategy for recruitment in this study, positive staff characteristics were identified by fathers as a support for remaining in the study, particularly once the program ended and participants were in long-term follow-up. For example, two fathers recount their relationship with staff members as supportive and distinct to their experience in the program.

So you know, yeah it was the help that came behind the free food and it's like, it's like, you know, it's actually people that want to see you succeed. They're not just 
doing their job. They're people that's really sitting there behind you, hey did you go to that interview? Do you need a ride to that interview? Do you need clothes for that interview?

Staff relationships were identified as important to fathers throughout the study, and may be underemphasized in traditional literature on enrolling and retaining low-income fathers in longitudinal prevention research.

Flexible communications. Multiple methods of communication were used to support participant retention, including texting, calling, and in-person visits. One father explained that using text messages to confirm appointments was one way he was able to stay connected with the program, saying "So, me and the instructors, we kinda close. Like, before program starts, I either text him or call him to check if there's a program." In addition to flexible communication, staff also made efforts to have contact information and permission for other potential points of contact for each father in the study. This assisted with contacting participants for data follow-ups once the 15-week program had ended. Staff used various points of contact, such as family or friends, in order to support retention. Upon obtaining informed consent at the time of the baseline interview, outreach specialists asked respondents to provide detailed information so that they could be contacted for follow-up visits and data collection. Information collected on the form included the individual's most current phone number(s), email, current address, and usual hangout. Most importantly, contact information was collected for at least one friend or relative of the respondent. This person would be someone who would serve as a contact person in case staff needed to locate the respondent and could not find them using their own contact information. This latter data proved to be strategically significant given the sample was highly mobile during the course of the study.

Project staff made sure that the participant understood the importance of follow-up data collection being essential and integral to the research, a point that was highlighted in the informed consent procedure. When the above strategies did not yield results, research and outreach staff made phone calls and personal visits to homes. Phone calls were used in two ways. First, the day before the scheduled follow-up data collection, outreach specialists would make reminder phone calls with those with valid numbers. Phone calls were also used as a way to maintain contact with respondents between follow-ups. This was especially the case for those that had valid phone numbers and contributed to maintaining the staff-participant relationship. Staff members also made personal visits to participants' homes. One father recounts his experience with a staff member working to re-engage him in the study:

One way that I felt accepted, or one experience, um, that happened, where I felt accepted was when I wasn't really buying into the program and one of the staff members just basically kept like, kept trying to get me involved. You know what I'm saying? Like, he showed up at the house, he called me...You know, he told me something and it was, it was crazy, 'cause it was like, I never really heard nobody, it's one of the reasons why I'm here today, to be honest with you. It's, he told me, he said I'm never gone give up on you. He said there's too many of that going on, there's too much of that going on right now. 
These home visits further contributed to the research team's "street presence." This street presence facilitated the process of maintaining trust and rapport with the participants. Additionally, the location of the field office within the same geographic area where recruitment was taking place contributed to the interaction of staff and respondents on a regular basis. The home-visiting strategy was particularly critical during the months in between follow-ups, when participant retention and communication was more likely to drop off.

\section{Identified Barriers and Solutions}

Recruitment. Participants identified further community outreach strategies that could be used to support recruitment for the study, including more street-level outreach that demonstrated community involvement and investment. Participants suggested that getting involved in local basketball games and speaking on popular radio stations may boost enrollment. In addition, participants suggested more outreach attempts on social media sites. One father noted that this was a way to reach out to the generation of young men and fathers. "Well you know, kids my generation, you know like to Facebook, to Twitter, and you know, I think that if they can create like social sites." Participants also suggested onetime information sessions for fathers, providing concrete parenting information and serving as gateways to the larger program.

Retention. Despite the extensive efforts to support recruitment and retention in this study, there were still relatively high rates of attrition, with only $41 \%$ of participants responding to the 16-month follow-up survey. However, these rates were consistent with other recent longitudinal studies of pregnancy prevention (Corcoran \& Pillai, 2007). Study participants noted transportation and weather were strong barriers to retention for participants. "Transportation and the weather. That's the only thing I can say, cause if it's raining I will not show up. Knowing that I gotta take the bus from my house here, I won't show up. " One father suggested providing transportation to participants as a strategy to overcome the transportation barrier. Future studies may provide bus passes, or a central van pick-up location at key city spots, as strategies to enhance retention. Follow-up visits, home visits for data collection, or data collection at central community locations may be more practical and feasible, and may eliminate transportation barriers for longitudinal follow-ups.

Employment, and most specifically work schedules, were also identified as a barrier to program completion. Fathers noted program times would conflict with work schedules, causing them to miss group and potentially leave the program. One father discussed the challenges of balancing the program with a third shift position. "...I work third shift and the mornings were like, I'm dead (laughing). You know what I'm saying? So, yeah that was hard." Although not directly noted by participants, flexible program hours such as morning or evening sessions may be a strategy to overcoming this barrier.

\section{Discussion}

This study builds upon the existing literature by including perspectives from young minority fathers and providers engaged in a randomized control trial of an early fatherhood 
prevention programs to the existing literature base. Recruitment strategies such as advertisement and incentives identified by other fathers (Stahlschmidt et al., 2013) were also identified as helpful by the fathers in this study. Advertisement and outreach was a major recruitment strength identified by participants. In fact, fathers suggested even broader community outreach, such as engagement through social media and informal community activities, such as basketball games. This type of extensive recruitment and outreach may be particularly developmentally appropriate for young fathers. Additionally, fathers noted that financial incentives and job training were incentives for both recruitment and retention in the program.

Some recruitment strategies identified by the fathers in this study that have not been identified in the broader research are using flexible communication and the importance of the relationship with staff. Participants identified that being able to text or call a program staff member was particularly helpful to supporting retention in the program. Participants also identified the importance of having a relationship with the staff; fathers reported that they felt supported by the caring relationships with staff. The importance of relationships may be of particular significance for young fathers who may not have informal support networks in their role as fathers. Participants noted feeling heard and understood by program staff, and identified this relationship and communication as central to retention. This is an important finding in terms of program development in community-based programs, where staff turnover may be a barrier to continued relationship development and support of clients and participants. Other research on enhancing father engagement indicates that fathers use humor and personal stories more in parenting groups and this may be helpful in further program development (Frank, Keown, \& Sanders, 2015). Another successful strategy employed in this study was adopting community-organizing ideologies and strategies. These community-organizing events not only helped to build an alliance and a bridge between fathers, services, research, and the community, but they also helped to encourage behaviors that lead to more interaction with community services and programs. By adopting community-organizing tools and strategies, along with successfully incorporating social media, and other flexible communication techniques, we can increase participation of groups and communities by rebuilding that trust and through renegotiating relationships that are rooted in mutual respect and trust.

Over the past decade there has been increasing interest in understanding the role of the young father in condom negotiation and partner communication to decrease future pregnancies (Horn, 2003; McBride \& Lutz, 2004; Mogro-Wilson et al., 2018). Despite this progress, there remain many methodological challenges in conducting studies with fathers. This paper highlighted several methodological barriers and strategies for how this project overcame these barriers, including recruitment strategies, enrollment and retention barriers, and those overarching issues that have persisted throughout the project. While traditional recruitment and retention methods, such as incentives, were employed in this study, nontraditional methods were used as well, such as intensive community outreach, staff relationship development, recruiting specialists, and flexible contact methods. Although limited through a small sample size, this study gives conceptual backing for future adaptations to interventions to support hard-to-reach young fathers. The use of culturally adapted social work interventions has also been touted as a responsive way to support equal 
opportunity and justice for Latino/as in the recent Grand Challenges identified by the American Academy of Social Work and Social Welfare (Calvo et al., 2016). Social workers may play a key role in pregnancy prevention and parenting programs for young, minority fathers by emphasizing inclusive and non-traditional recruitment strategies and meeting the needs of young fathers through incentives such as transportation in order to support engagement through the course of a parenting program.

\section{References}

Aggleton, P., \& Campbell, C. (2000). Working with young people — towards an agenda for sexual health. Sexual and Relationship Therapy, 15, 283-296. doi: https://doi.org/10.1080/14681990050109863

Anderson, E. A., Kohler, J. K., \& Letiecq, B. L. (2002). Low-income fathers and "responsible fatherhood" programs: A qualitative investigation of participants' experiences. Family Relations, 51(2), 148-155. doi: https://doi.org/10.1111/j.17413729.2002.00148.x

Mogro-Wilson, C., Drake, A., Coman, E., Sanghavi, T., Martin-Peele, M., \& Fifield, J. (2018). Increasing condom usage for African American and Hispanic young fathers in a community based intervention. Ethnicity and Health. doi: https://doi.org/10.1080/13557858.2018.1427704

Mogro-Wilson, C., \& Fifield, J. (2018). Engaging young minority fathers in research: Basic needs, psychological needs, culture, and therapeutic alliance. American Journal of Public Health, 108(S1), S15-16.

Bailey, J., Bieniasz, M., Kmak, D., Brenner, D., \& Ruffin, M. (2004). Recruitment and retention of economically underserved women to a cervical cancer prevention trial. Applied Nursing Research, 17, 55-60. doi: https://doi.org/10.1016/j.apnr.2003.12.002

Becker, D., Hogue, A., \& Liddle, H. A. (2002). Methods of engagement in family-based preventive intervention. Child and Adolescent Social Work Journal, 19(2), 163-179. doi: https://doi.org/10.1023/A:1014550507467

Bookchin, M. (2005). The ecology of freedom: The emergence and dissolution of hierarchy. Oakland, CA: AK Press.

Bronte-Tinkew, J., Burkhauser, M., \& Metz, A. (2007). What works in fatherhood programs? Ten lessons from evidence-based practice. Gaithersburg, MD: National Responsible Fatherhood Clearinghouse.

Burrus, B. B. (2018). Decline in adolescent pregnancy in the United States: A success not shared by all. American Journal of Public Health, 108(S1), S5-6. doi: https://doi.org/10.2105/AJPH.2017.304273

Buston, K., Parkes, A., Thomson, H., Wight, D., \& Fenton, C. (2012). Parenting interventions for male young offenders: A review of the evidence on what works. Journal of Adolescence, 35(3), 731-742. doi: https://doi.org/10.1016/j.adolescence.2011.10.007 
Caldwell, C. H., Bell, L., Brooks, C. L., Ward, J. D., \& Jennings, C. (2011). Engaging nonresident African American fathers in intervention research: What practitioners should know about parental monitoring in nonresident families. Research on Social Work Practice, 21(3), 298-307. doi: https://doi.org/10.1177/1049731510382923

Calvo, R., Ortiz, L., Padilla, Y., Waters, M., Lubben, J., Egmont, W.,...Villa, P. (2016). Achieving equal opportunity and justice: The integration of Latina/o immigrants into American society. American Academy of Social Work and Social Welfare: Grand Challenges of Social Work Initiative. Retrieved from http://aaswsw.org/grandchallenges-initiative/12-challenges/achieve-equal-opportunity-and-justice/

Carlson, M. J., \& Magnuson, K. A. (2011). Low-income fathers' influence on children. The Annals of the American Academy of Political and Social, 635(1), 95-116. doi: https://doi.org/10.1177/0002716210393853

Centers for Disease Control and Prevention. (2013). Vital signs: Repeat births among fathers in the United States, 2007-2010. Retrieved from https://www.cdc.gov/mmwr/preview/mmwrhtml/mm6213a4.htm

Chacon, J., Patterson, K., Brown, C., \& Bavolek, S. (2003). 24/7 Dad A.M.: Fathering handbook. Germantown, MD: National Fatherhood Initiative.

Corbie-Smith, G., Thomas, S. B., \& St. George, D. M. (2002). Distrust, race, and research. Archives of Internal Medicine, 162(21), 2458-2463. doi: https://doi.org/10.1001/archinte.162.21.2458

Corcoran, J., \& Pillai, V. K. (2007). Effectiveness of secondary pregnancy prevention programs: A meta-analysis. Research on Social Work Practice, 17(1), 5-18. doi: https://doi.org/10.1177/1049731506291583

Cowan, P. A., Cowan, C. P., Pruett, M. K., Pruett, K. D., \& Wong, J. (2009). Promoting fathers' engagement with children: Preventative interventions for low-income families. Journal of Marriage \& Family, 71, 663-679. doi: https://doi.org/10.1111/j.1741-3737.2009.00625.x

Dubowitz, H., Black, M., Cox, C., Kerr, M., Litrownik, A., Radhakrishna, A.,... Runyan, D. K. (2001). Father involvement and children's functioning at age 6 years: A multisite study. Child Maltreatment, 6(4), 300-309. doi: https://doi.org/10.1177/1077559501006004003

Farr, M., \& Pavlicko, M. A. (2006). Young person's guide to getting and keeping a good job. Indianapolis, IN: JIST Publishing.

Fletcher, R., Freeman, E., \& Matthey, S. (2011). The impact of behavioural parent training on fathers' parenting: A meta-analysis of the Triple P-Positive Parenting Program. Fathering, 9, 291-312. doi: https://doi.org/10.3149/fth.0903.291

Frank, T. J., Keown, L. J., \& Sanders, M. R. (2015). Enhancing father engagement and interparental teamwork in an evidence-based parenting intervention: A randomizedcontrolled trial of outcomes and processes. Behavior Therapy, 46, 749-763. doi: https://doi.org/10.1016/j.beth.2015.05.008 
Froelicher, E., Miller, N., Buzaitis, A., Pfenninger, P., Misuraco, A., \& Jordan, S. (2003). The enhancing recovery in coronary heart disease trial: Strategies and techniques for enhancing retention of patients with acute myocardial infarction and depression or social isolation. Journal of Cardiopulmanary Rehabilitation, 23(4), 269-280. doi: https://doi.org/10.1097/00008483-200307000-00004

Gordon, D. M., Hunter, B., Woods, L. N., Tinney, B., Bostic, B., Malone, S.,...Smith, A. (2012). Increasing outreach, connection, and services to low-income, non-custodial fathers: How did we get here and what do we know. Fathering, 10(1), 101-111. doi: https://doi.org/10.3149/fth.1001.101

Gordon, J. A., Shaffer, D. W., Raemer, D. B., Pawlowski, J., Hurford, W. E., \& Cooper, J. B. (2006). A randomized controlled trial of simulation-based teaching versus traditional instruction in medicine: A pilot study among clinical medical students. Advances in Health Sciences Education, 11, 33-39. doi: https://doi.org/10.1007/s10459-004-7346-7

Hamilton, B. E., Martin, J. A., \& Osterman, M. J. K. (2016). Births: Preliminary data for 2015. National Vital Statistics Report, 65(3), 1-15.

Horn, W. (2003). Is it working? Early evaluations of fatherhood renewal programs. In O. Clayton, R. B. Mincy, \& D. Blankenhorn (Eds.), Black fathers in contemporary society: Strengths, weaknesses, and strategies for change (pp. 138-152). New York: Russell Sage Foundation.

Jeynes, W. H. (2015). A meta-analysis: The relationship between father involvement and student academic achievement, Urban Education, 50(4), 387-423. doi: https://doi.org/10.1177/0042085914525789

Katz, K., El-Mohandes, P., Johnson, D., Jarrett, P., Rose, A., \& Cober, M. (2001). Retention of low income mothers in a parenting intervention study. Journal of Community Health, 26, 203-218. doi: https://doi.org/10.1023/A:1010373113060

Khurana, A., \& Gavazzi, S. M. (2011). Juvenile delinquency and adolescent fatherhood. International Journal of Offender Therapy and Comparative Criminology, 55(5), 756-770. doi: https://doi.org/10.1177/0306624X10372109

Lewin, A., Mitchell, S. J., Burrell, L., Beers, L. S. A., \& Duggan, A. K. (2011). Patterns and predictors of involvement among fathers of children born to adolescent mothers. Journal of Family Social Work, 14(4), 335-353. doi: https://doi.org/10.1080/10522158.2011.587178

Lundahl, B. W., Tollefson, D., Risser, H., \& Lovejoy, M. C. (2004). A meta-analysis of father involvement in parent training. Research on Social Work Practice, 18(2), 97106. doi: https://doi.org/10.1177/1049731507309828

Martinez, G. M., Chandra, A., Abma, J. C., Jones, J., \& Mosher, W. D. (2006). Fertility, contraception, and fatherhood: Data on men and women from the 2002 National Survey of Family Growth. Vital and Health Statistics, 23, 1-142. Retrieved from https://www.cdc.gov/nchs/data/series/sr_23/sr23 026.pdf 
McBride, B. A., \& Lutz, M. M. (2004). Intervention: Changing the nature and extent of father involvement. In M. E. Lamb (Ed.), The role of the father in child development ( $4^{\text {th }}$ ed., pp. 664-475). New York: Wiley.

Miles, M. B., Huberman, A. M., \& Saldana, J. (2013). Qualitative data analysis (3rd ed.). Thousand Oaks, CA: Sage.

Milkie, M. A., \& Denny, K. E. (2014). Changes in the cultural model of father involvement descriptions of benefits to fathers, children, and mothers in parents' magazine, 1926-2006. Journal of Family Issues, 35(2), 223-253. doi: https://doi.org/10.1177/0192513X12462566

Padgett, D. (2008). Qualitative methods in social work research ( $2^{\text {nd }}$ ed.). Thousand Oaks, CA: Sage.

Palm, G., \& Fagan, J. (2008). Father involvement in early childhood programs: Review of the literature. Early Childhood Development and Care, 178(7-8), 745-759. doi: https://doi.org/10.1080/03004430802352137

Parra-Medina, D., D’antonio, A., Smith, S., Levin, S., Kirkner, G., \& Mayer-Davis, E. (2004). Successful recruitment and retention strategies for a randomized weight management trial for people with diabetes living in rural medically underserved counties of South Carolina: The POWER study. Journal of American Dietetic Association, 104, 70-75. doi: https://doi.org/10.1016/j.jada.2003.10.014

Robinson, K. A., Dennison, C. R., Wayman, D. M., Pronovost, P. J., \& Needham, D. M. (2007). Systematic review identifies number of strategies important for retaining study participants. Journal of Clinical Epidemiology, 60(8), 757-757. doi: https://doi.org/10.1016/j.jclinepi.2006.11.023

Smith, T. K., Duggan, A., Bair-Merritt, M. H., \& Cox, G. (2012). Systematic review of fathers' involvement in programmes for the primary prevention of child maltreatment. Child Abuse Review, 21(4), 237-254. doi: https://doi.org/10.1002/car.2195

Spoth, R., \& Redmond, C. (2000). Research on family engagement in preventive intervention: Toward improved use of scientific findings in primary prevention practice. The Journal of Primary Prevention, 21(2), 267-284. doi: https://doi.org/10.1023/A:1007039421026

Stahlschmidt, M. J., Threlfall, J., Seay, K. D., Lewis, E. M., \& Kohl, P. L. (2013). Recruiting fathers to parenting programs: Advice from dads and fatherhood program providers. Children and Youth Services Review, 35(10), 1734-1741. doi: https://doi.org/10.1016/j.childyouth.2013.07.004

Travaline, J. M., Ruchinskas, R., \& D’Alonzo, G. E. (2005). Patient-physician communication: Why and how. Journal of the American Osteopathic Association, 105(1), 13-18.

Trivedi, D., Bunn, F., Graham, M., \& Wentz, R. (2007). Evidence from the systematic reviews. In P. Baker, K. Guthrie, C. Hutchinson, R. Kane, \& K. Wellings (Eds.), 
Teenage pregnancy and rep health (pp. 275-291). London: Royal College of Obstetrics and Gynaecology Press.

Trivedi, D., Brooks, F., Bunn, F., \& Graham, M. (2009). Early fatherhood: A mapping of the evidence base relating to pregnancy prevention and parenting support. Health Education Research, 24(6), 999-1028. doi: https://doi.org/10.1093/her/cyp025

Tully, L. A., Collins, L. A., Piotrowska, P. J., Mairet, K. S., Hawes, D. J., Moul, C., ... Dadds, M. R. (2018). Examining practitioner competencies, organizational support and barriers to engaging fathers in parenting interventions. Child Psychiatry \& Human Development, 49(1), 109-122. doi: https://doi.org/10.1007/s10578-017-0733$\underline{0}$

Xie, H., Cairns, B. D, \& Cairns, R. B. (2001). Predicting teen motherhood and teen fatherhood: Individual characteristics and peer affiliations. Social Development, 10(4), 488-511. doi: https://doi.org/10.1111/1467-9507.00177

Author note: Address correspondence to: Cristina Mogro-Wilson, PhD, MSW, School of Social Work, University of Connecticut, 38 Prospect Street, Hartford, CT 06103. cristina.wilson@uconn.edu 